\title{
Preventive effects of protopanaxadiol and protopanaxatriol ginsenosides on liver inflammation and apoptosis in hyperlipidemic apoE KO mice
}

\author{
Soojeong Jang • Yunsook Lim • Giuseppe Valacchi • \\ Sungbin Sorn · Hyon Park • Na-Young Park • \\ Myoungsook Lee
}

Received: 28 April 2011/Accepted: 6 August 2011/Published online: 19 August 2011

(C) Springer-Verlag 2011

\begin{abstract}
Ginsenosides, bioactive compounds of Panax Ginseng C.A. Meyer, are divided into protopanaxadiol (PD) and protopanaxtriol (PT). The aim of this study was to evaluate the protective effects of different PD and PT combination ratios on liver inflammation and apoptosis in hyperlipidemic apo E KO mice. $\mathrm{R} 1\left(\mathrm{PD} / \mathrm{PT}=1\right.$, high $\mathrm{Rg}_{1}$ and $\left.\mathrm{Rb}_{1}\right)$ and $\mathrm{R} 2(\mathrm{PD} / \mathrm{PT}=2$, high $\mathrm{Re}$ and $\mathrm{Rd})$ extracts were intraperitoneally injected by $100 \mathrm{mg} / \mathrm{kg} /$ day at the 8 th week. $\mathrm{R} 1$ and R2 improved atherogenic indices by increasing HDL and lowering total cholesterol (TC) and triacylglyceride (TG) selectively. R1 decreased lipid peroxides (LPO) level in plasma and liver tissue of hyperlipidemic mice, and R2 lowered plasma malondialdehyde(MDA) level. R1 and R2 not only regulated the expression of cyclooxygenase (COX)2 , I $\kappa$ B- $\alpha$, phopho-ERK 1/2, and phopho-SAPK/JNK levels but also were significantly effective in blocking apoptotic
\end{abstract}

Myoungsook Lee is corresponding author and Yunsook Lim is co-corresponding author.

S. Jang · M. Lee $(\bowtie)$

Department of Food and Nutrition, Nutrition Biochem Lab,

Sungshin Women's University, \#249-1, 3-ga, Dongsun-dong,

Sungbuk-ku, Seoul 136-742, Republic of Korea

e-mail: mlee@ sunghsin.ac.kr

S. Jang

Korean Food Research Institute, Sungnam, Gyeonggi-do, Republic of Korea

Y. Lim $(\bowtie) \cdot$ G. Valacchi · N.-Y. Park

Department of Food and Nutrition, Kyung Hee University,

\#1 Hoegi-dong, Dongdaemun-gu, Seoul 130-701,

Republic of Korea

e-mail: ylim@khu.ac.kr

G. Valacchi

Department of Biomedical Sciences, University of Siena,

53100 Siena, Italy signals, such as caspase- $8,-9$, as well as the cleavage of PARP in liver. Different combinational treatment of PD and PT extracts might ameliorate the liver inflammation and apoptosis in hyperlipidemic apo E KO mice, which is atherosclerotic animal model.

Keywords Ginsenosides - Apoptosis - Apo E KO mice · $\mathrm{LPO} \cdot \mathrm{NF} \kappa \mathrm{B} \cdot \mathrm{MAPK} \cdot$ Caspase $\cdot$ Cleaved PARP $\cdot \mathrm{Bcl}-2$. Hyperlipidemia

\section{Introduction}

Nowadays, poor eating habits, particularly those involving high dietary fat and cholesterol intake, have led to a rapid increase in the incidence of health problems, such as hyperlipidemia and obesity (Bray and Popkin 1998; Formiguera and Canton 2004). Chronic consumption of the diet described alters the plasma and tissue levels of

\section{S. Sorn}

Department of Biological Sciences, College of Life Science and Bioengineering, Korea Advanced Institute of Science and Technology, Daejeon city, Republic of Korea

H. Park

Department of Sport Medicine, College of Physical Education, Kyung Hee University, Yongin, Republic of Korea

M. Lee

Research Institute of Obesity Science,

Sungshin Women's University, Seoul, Republic of Korea 
cholesterol and triglyceride and results in a higher risk for liver disease (Pendino et al. 2005; Wouters et al. 2008; Ferre et al. 2009). Although several types of evidence suggest that hyperlipidemia may not appear to impair liver function, it may affect the severity of tissue injury by increasing the vulnerability of the liver to the harmful effects of cytokines and oxidative agents (Jou et al. 2008; Farrell and Larter 2006). Previous research in experimental models of hyperlipidemia has shown that inflammatory gene expression in liver is induced by increased plasma cholesterol and modified lipoprotein levels (Pendino et al. 2005; Wouters et al. 2008; Ferre et al. 2009). It has been demonstrated that nuclear factor kappa-B $(\mathrm{NF} \kappa \mathrm{B})$ may play a role in the development of hyperlipidemia-related chronic diseases by modulating the expression of various cytokines and adhesion molecules (Valen et al. 2001). In addition to $\mathrm{NF} \kappa \mathrm{B}$, mitogen-activated protein kinases (MAPKs) are a group of signaling molecules that are involved in inflammatory cytokines production (Pearson et al. 2001; Ajizian et al. 1999). Three MAPK cascades are well described: (1) extracellular signal-regulated kinase (ERK) 1/2, (2) p38, (3) c-Jun N-terminal kinase (JNK)/stress-activated protein kinase (SAPK), which regulates immune responses, including inflammatory cytokine production (Boulton et al. 1991; Lee et al. 1994; Kyriakis et al. 1994). Furthermore, $\mathrm{NF} \kappa \mathrm{B}$ and MAPK cascades have been associated with the control of cell apoptosis through transcriptional regulation of adhesion molecules and cytokines (Chen and Greene 2004). Therefore, it is considered to be of benefit to reduce the risk of hepatic injury in hyperlipidemia by blunting the inflammatory response and impeding apoptosis in liver.

Panax ginseng C.A. Meyer (Ginseng) has been used for several 1,000 years to prolong longevity in Asian countries (Liu and Xiao 1992). It has been used as a "cure-all" in Asia and as an adaptogenic herb or a food supplement in Western countries (Xie et al. 2005; Mayr et al. 2004). Ginsenoside in ginseng, namely triterpenoidal dammarane saponin, which is uniquely present in the Panax species, is divided into protopanaxadiols (PDs) and protopanaxatriols (PTs). The PDs, including ginsenoside Rb1, Rb2, Rc, and Rd, have an anti-obesity effect (Liu et al. 2010; Kim et al. 2009) and exhibit anti-inflammatory activity (Lee et al. 2005), whereas the PTs, such as ginsenoside Re, Rf, and $\mathrm{Rg} 1$, have efficacy on the prevention of oxidative stress (Kwok et al. 2010) and the modulation of inflammatory processes (Oh et al. 2004). These reports show that each ginsenoside has different biological effects, but their synergetic properties in hyperlipidemia have not been examined so far. Although ginsenosides might attenuate hyperlipidemia-related chronic diseases, such as atherosclerosis, via an anti-inflammatory action and regulation of the blood lipid profiles (Liu et al. 2009, 2010; Wan et al. 2009), there are no studies on the effects of the PDs and
PTs ginsenosides combination on liver inflammation in hyperlipidemia. The purposes of this work were to evaluate the protective effects of a combination of PDs and PTs ginsenosides on liver inflammation and apoptosis in an in vivo hyperlipidemic model, apoE null $(\mathrm{KO})$ mice that were fed a high-cholesterol diet.

\section{Materials and methods}

Animals and treatment

Male apoE KO mice with wild-type C57BL/6 were purchased from Japan SLC Incorporation (Tokyo, Japan), which were kept both for 12 weeks on a high-cholesterol diet $(1.25 \%$ cholesterol, $7.5 \%$ cocoa butter, $0.5 \%$ sodium cholate, DYET\#102068; Dyets Inc., Bethelehem, PA, USA) (Guo et al. 2005). On the 8th week post induction of hyperlipidemia, the mice were intraperitoneally (i.p.) injected with ginseng extracts (100 mg/kg/day) for 4 weeks. Experiments were performed in accordance with the guidelines of the Committee on Animal Care at Sungshin Women's University. At the end of the study period, the animals were euthanized, and plasma samples were obtained along with the different tissues.

\section{Preparation of ginseng extracts}

Ginseng extracts were obtained from the Korean Food Research Institute (Gyeonggi-do, Republic of Korea) and prepared using a modification of a previously published method (Shibata et al. 1966). Four-year-old ginseng plant roots (Anseong Nonghyup, Republic of Korea) were separated into the main body, lateral, and fine parts. R1 samples (PDs:PTs = 1:1) were made with the main-to-lateral ratio of 5:1, while R2 (PDs:PTs = 2:1) samples were made with the lateral-to-fine ratio of 1:5. The same amounts of different parts of the roots $(2 \mathrm{~g})$ were heat-dried for 7 days at $60^{\circ} \mathrm{C}$, ground in a Gold HM-5000 (Mixer, 30 mesh) (Hyundae Co., Incheon, Republic of Korea), and extracted with $100 \mathrm{ml}$ of $80 \%$ ethanol. During extraction, the samples twice underwent the process using a circulating condenser for $3 \mathrm{~h}$ each, at $80^{\circ} \mathrm{C}$ (Korea Food Research Institute). Extracts were concentrated under reduced pressure and used over the 65 brix. HPLC analysis was used to identify the ginsenosides in $\mathrm{R} 1$ and R2, showing that R1 contained the richest amounts of $\mathrm{Rg}_{1}(\mathrm{PT})$ and $\mathrm{Rb}_{1}(\mathrm{PD})$, while $\mathrm{R} 2$ contained the richest amounts of Re (PT) and Rd (PD) (Fig. 1a, b).

Measurement of lipid profiles

Lipid profiles for total cholesterol (TC) and triacylglyceride (TG) were measured in plasma and liver tissue. TC 
Fig. 1 The distribution of ginsenosides in R1 and R2 ginseng extracts identified by HPLC (a). The inserted table in Fig. 1 a provides the HPLC conditions used. R1 contained higher contents of $\mathrm{Rb}_{1}$ and $\mathrm{Rg}_{1}$, while R2 contained higher levels of $\operatorname{Rd}$ and $\operatorname{Re}(\mathbf{b})$. The fourteen standards of ginsenosides included compounds $\mathrm{K}, \mathrm{Rh}_{2}, \mathrm{Rh}_{1}, \mathrm{Rg}_{5}$, $\mathrm{Rk}_{1}, \mathrm{Rg}_{2}, \mathrm{Rg}_{3}, \mathrm{Rg}_{1}, \mathrm{Rf}, \mathrm{Re}, \mathrm{Rd}$ $\mathrm{Rb}_{2}, \mathrm{Rc}$, and $\mathrm{Rb}_{2}$, which were provided by Daedeck Science Town, Daejeon, Republic of Korea
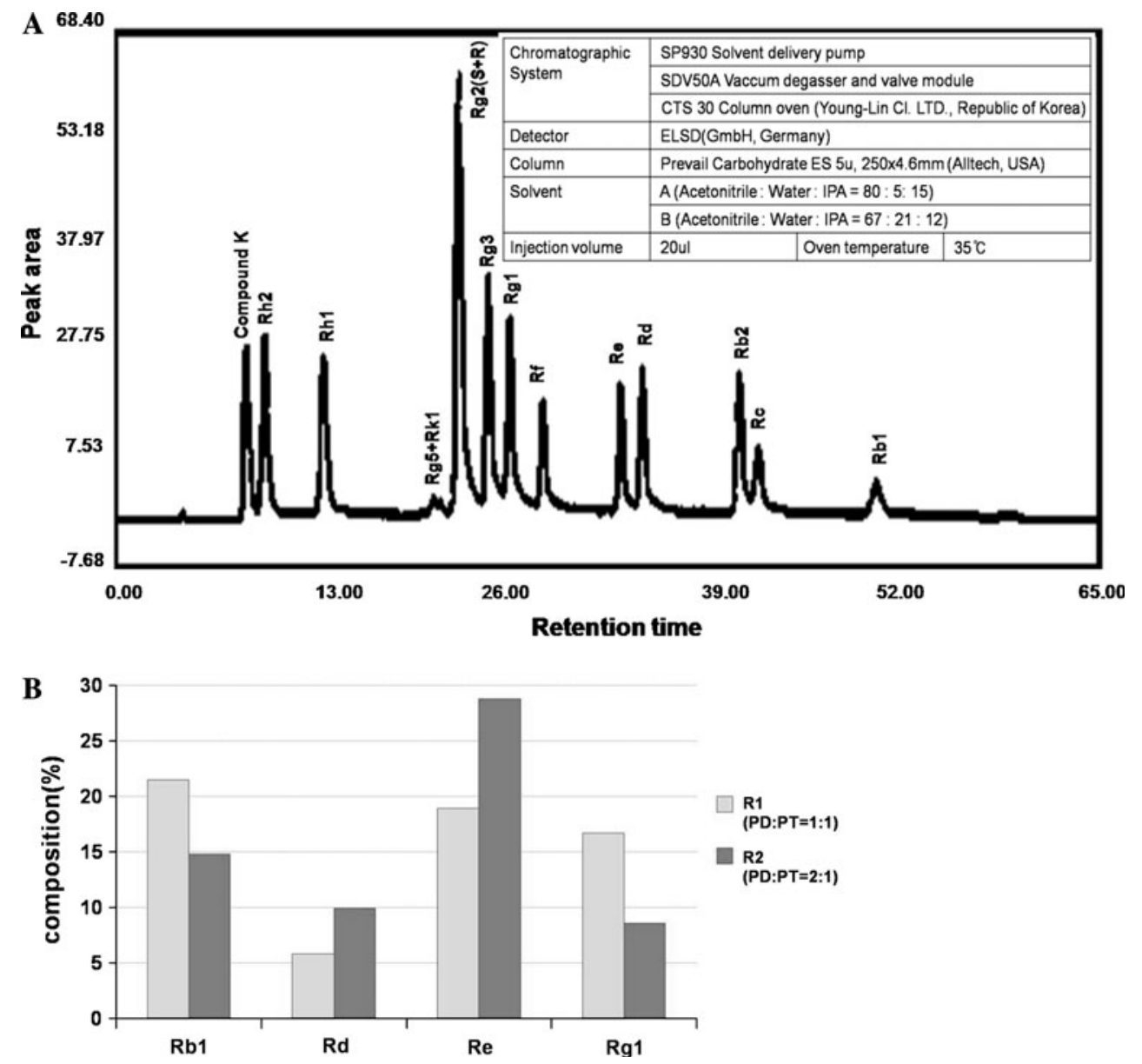

and TG determinations were measured with enzymatic colorimetric methods (ASSEL S.r.l., Guidna, Italy) (Vassault et al. 1981). High-density lipoprotein cholesterol (HDL) levels were also measured with an enzymatic colorimetric method (Daiichi Pure Chemicals Co., Ltd. Tokyo, Japan) (Gordon et al. 1977).

\section{Oxidative stress indicators}

Lipid peroxides (LPO) and malondialdehyde (MDA) were measured as representative metabolites derived from the peroxidation of dietary poly-unsaturated fatty acids (PUFA). LPO and MDA levels were measured using a microplate assay kit (\# fr22; Oxford Biochemical Research, Oxford, MI, USA) as previously reported by Lee and Bae (2007).

\section{Western blot analysis}

Liver samples were homogenized in lysis buffer $(\mathrm{pH} 7.4$, $10 \% \mathrm{v}: \mathrm{v}$ ) containing $1 \mathrm{M}$ Tris, $5 \mathrm{M} \mathrm{NaCl}$, and $0.1 \mathrm{M}$ EDTA. The homogenates were then centrifuged at 15,000 rpm for
$45 \mathrm{~min}$ at $4^{\circ} \mathrm{C}$. The cytosol fraction was boiled for $5 \mathrm{~min}$ at $95^{\circ} \mathrm{C}$ with a sodium dodecyl sulfate-loading buffer. Proteins were fractioned by SDS-polyacrylamide gel electrophoresis and transferred to nitrocellulose membranes (\#401296; Schleicher \& Schuell, Dassel, Germany). The membrane was incubated with a primary antibody (Cell signaling, Beverly, MA) that reacted with a horseradish peroxidaseconjugated secondary antibody (Cell signaling, Beverly, MA). The primary antibodies were rabbit anti-COX-2, rabbit anti-I $\kappa$ B- $\alpha$, rabbit anti-phospho-ERK1/2, rabbit anti-SAPK/ JNK, rabbit anti-phospho-c-Jun (Ser73), rabbit anti-Bcl-2, rabbit anti-caspase-8/-9, and rabbit anti-cleaved PARP. Antibody bindings were visualized by chemiluminescence with ECL kit (\#SC-2048; Santa Cruz Biotechology, Inc., Santa Cruz, CA, USA) and exposed to X-ray film (Kodak $\mathrm{XAR})$ to identify the target protein.

\section{Statistical analysis}

All values are shown as means \pm standard deviation (SD). Statistical significances were assessed using one-way analysis of variance (ANOVA) with Duncan's test. A $P$-value of 0.05 was considered significant. 
Table 1 Alterations of lipid profiles and atherogenic indices in plasma and liver tissues of apoE KO mice administrated with the R1 and R2 ginseng extracts

\begin{tabular}{|c|c|c|c|c|}
\hline & Wild-type & $\operatorname{ApoE}(-/-)$ & ApoE KO + R1 & ApoE KO + R2 \\
\hline \multicolumn{5}{|l|}{ Plasma } \\
\hline TG (mg/dl) & $223.2 \pm 63.0^{\mathrm{a}}$ & $1337.5 \pm 249.7^{\mathrm{c}}$ & $809.5 \pm 43.4^{\mathrm{b}}$ & $841.9 \pm 65.8^{b}$ \\
\hline $\mathrm{TC}(\mathrm{mg} / \mathrm{dl})$ & $76.4 \pm 22.1^{\mathrm{a}}$ & $380.4 \pm 65.7^{\mathrm{c}}$ & $279.1 \pm 31.3^{\mathrm{b}}$ & $364.6 \pm 41.4^{\mathrm{c}}$ \\
\hline HDL (mg/dl) & $33.8 \pm 15.8^{\mathrm{a}}$ & $77.2 \pm 5.4^{\mathrm{b}}$ & $109.3 \pm 10.6^{\mathrm{c}}$ & $106.7 \pm 7.1^{\mathrm{c}}$ \\
\hline AI-1 & $6.2 \pm 2.6^{\mathrm{a}}$ & $16.5 \pm 4.2^{\mathrm{b}}$ & $6.5 \pm 0.9^{\mathrm{a}}$ & $6.9 \pm 0.9^{\mathrm{a}}$ \\
\hline AI-2 & $7.2 \pm 2.6^{\mathrm{a}}$ & $17.5 \pm 4.2^{\mathrm{b}}$ & $7.5 \pm 0.9^{\mathrm{a}}$ & $7.9 \pm 0.9^{\mathrm{a}}$ \\
\hline \multicolumn{5}{|l|}{ Liver } \\
\hline TG (/protein $1 \mathrm{mg})$ & $39.9 \pm 9.0^{\mathrm{b}}$ & $39.5 \pm 5.4^{\mathrm{b}}$ & $30.5 \pm 5.5^{\mathrm{a}, \mathrm{b}}$ & $27.8 \pm 5.5^{\mathrm{a}}$ \\
\hline $\mathrm{TC}$ (/protein $1 \mathrm{mg}$ ) & $25.6 \pm 11.2$ & $20.5 \pm 2.2$ & $18.9 \pm 5.1$ & $18.3 \pm 4.1$ \\
\hline
\end{tabular}

Values are means \pm standard deviation of 4-8 mice per group

$T G$ triacylglyceride, $T C$ total cholesterol, $H D L$ high-density lipoprotein cholesterol, $A I-1$ atherogenic index-1, $A I-2$ atherogenic index-2

abc Means in the same row not sharing a common superscript are significantly different among groups at $P<0.05$

Table 2 The changes in production of lipid peroxides, LPO, and MDA in apoE KO mice treated with R1 and R2 ginseng extracts

\begin{tabular}{lcccc}
\hline & Wild-type & ApoE KO & ApoE KO + R1 & ApoE KO + R2 \\
\hline LPO & & & & \\
Plasma $(\mu \mathrm{mol} / \mu \mathrm{l})$ & $321.0 \pm 39.5^{\mathrm{a}}$ & $1197.3 \pm 134.3^{\mathrm{c}}$ & $1003.3 \pm 97.7^{\mathrm{b}}$ & $1051.5 \pm 224.8^{\mathrm{b}, \mathrm{c}}$ \\
Liver $(/$ protein $100 \mathrm{mg})$ & $38.7 \pm 11.1^{\mathrm{a}, \mathrm{b}}$ & $64.6 \pm 31.1^{\mathrm{b}, \mathrm{c}}$ & $35.6 \pm 4.7^{\mathrm{a}}$ & $50.4 \pm 10.0^{\mathrm{b}}$ \\
MDA & & & & \\
Plasma $(\mu \mathrm{molM} / \mu \mathrm{l})$ & $160.7 \pm 27.8^{\mathrm{a}}$ & $711.9 \pm 53.2^{\mathrm{c}}$ & $614.9 \pm 45.5^{\mathrm{b}}$ & $569.8 \pm 89.0^{\mathrm{b}}$ \\
Liver $(/$ protein $100 \mathrm{mg})$ & $23.4 \pm 1.9$ & $27.9 \pm 7.0$ & $27.7 \pm 2.8$ & $28.0 \pm 4.5$ \\
\hline
\end{tabular}

Data are means \pm SD values of 4-8 mice per group

LPO lipid hydroperoxide, $M D A$ malondialdehyde

abc Means in the same row not sharing a common superscript are significantly different among groups at $P<0.05$

\section{Results}

Lipid profiles and atherogenic indices

As shown in Table 1, the plasma TG concentration in the hyperlipidemic mice was significantly increased as compared to the wild-type control mice by 6-fold, but it was significantly decreased by the R1 and R2 treatments. The hepatic level of TG was not significantly different between the wild-type mice and the hyperlipidemic mice, but the R2 treatment showed a significant decrease in this level. The increase in plasma TC concentration was significantly attenuated by R1 treatment compared with the hyperlipidemic mice. Hepatic TC levels were not affected by the high-cholesterol diet or ginsenosides combination. While plasma HDL level was significantly increased in the hyperlipidemic mice compared to the wild-type control mice, this level was increased by 1.4-fold in both the R1 and R2 treatment groups. Moreover, the atherogenic indices significantly decreased in the groups in which R1 and
R2 were administered, as compared to the hyperlipidemic mice.

Effect of PDs and PTs ginsenosides combination on oxidative stress

As shown in Table 2, the plasma LPO level of the hyperlipidemic mice was significantly increased as compared with that of the wild-type control mice by 3.7 -fold. However, it was decreased by 0.8 -fold in the $\mathrm{R} 1$ treatment group. Hepatic LPO content in the R1 treatment mice decreased by 0.6-fold compared with the hyperlipidemic mice. Furthermore, the MDA level of plasma was markedly higher in the hyperlipidemic mice compared with the wild-type control mice $(160.7$ vs. $711.9 \mu \mathrm{M} / \mu \mathrm{l})$. However, the administration of R1 and R2 significantly lowered the level of plasma by 0.9 - and 0.8 -fold, respectively, compared to the hyperlipidemic mice. On the other hand, there was no significant difference in the MDA level in the liver between the hyperlipidemic mice and ginsenosides combination groups. 
Fig. 2 Changes in

inflammatory response in hepatic cytosol of

hyperlipidemic mice after treatment with R1 and R2 ginseng extracts having varying $\mathrm{PD} / \mathrm{PT}$ ratios. Differences between means were analyzed by one-way analysis of variance followed by Duncan's test $(P<0.05)$. The bars indicate the means $\pm \mathrm{SD}$
A
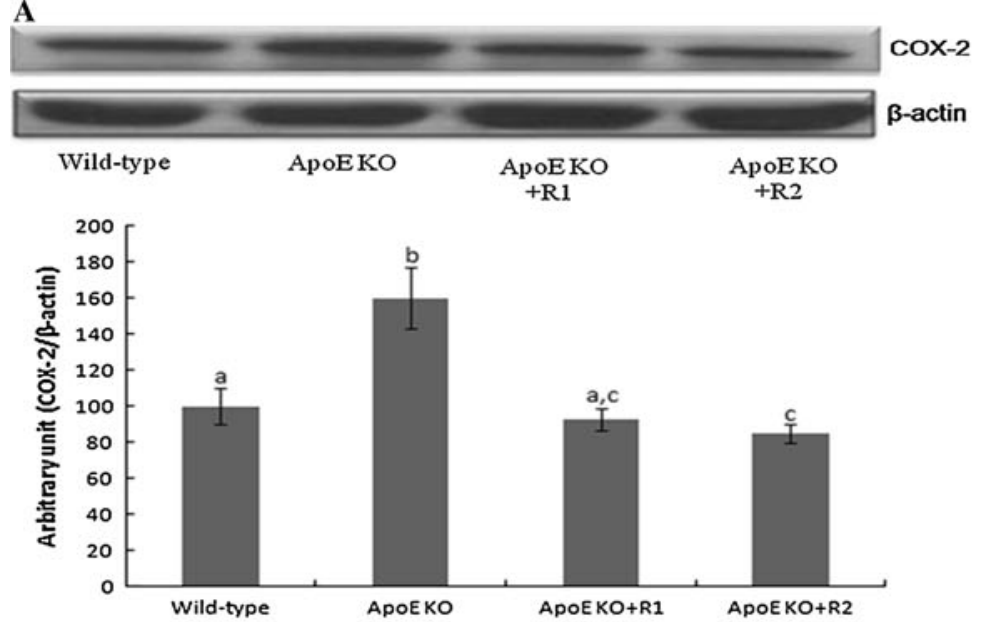

B
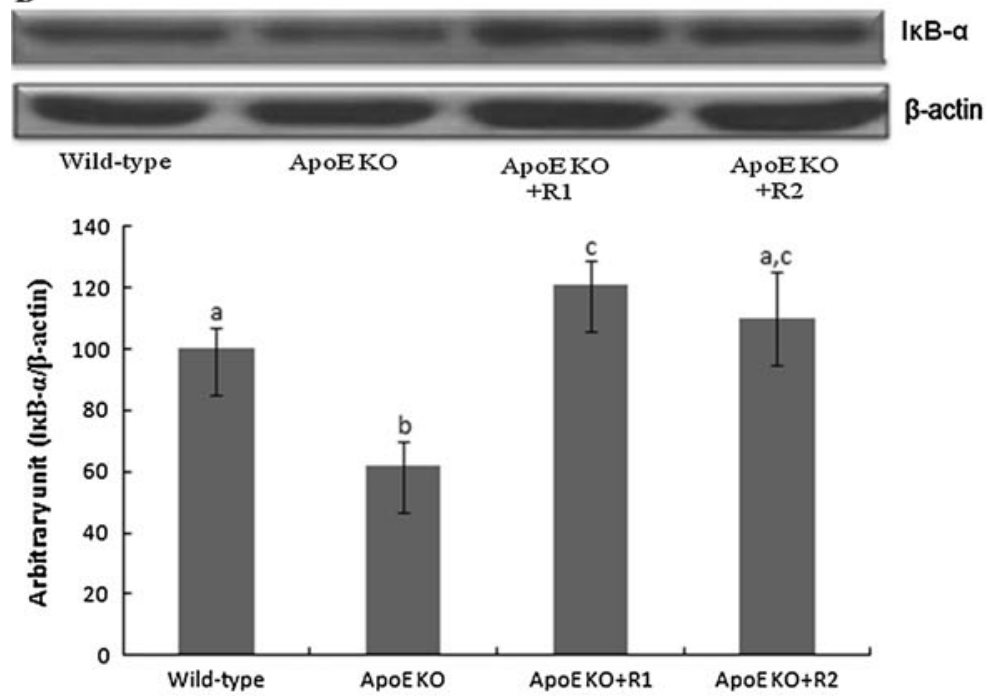

C

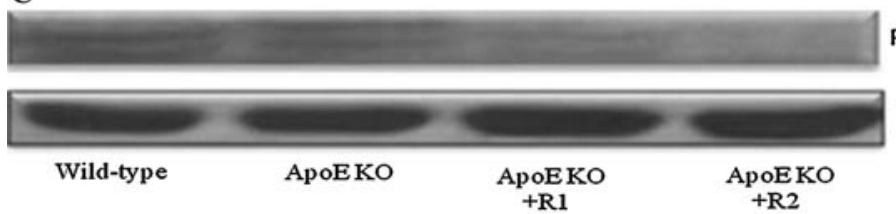

Phospho-ERK1/2

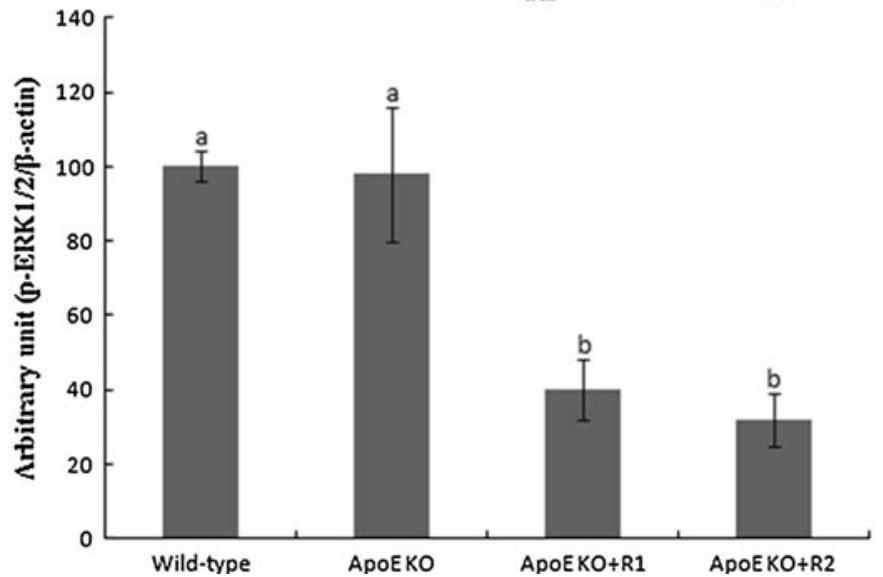


Fig. 2 continued

D
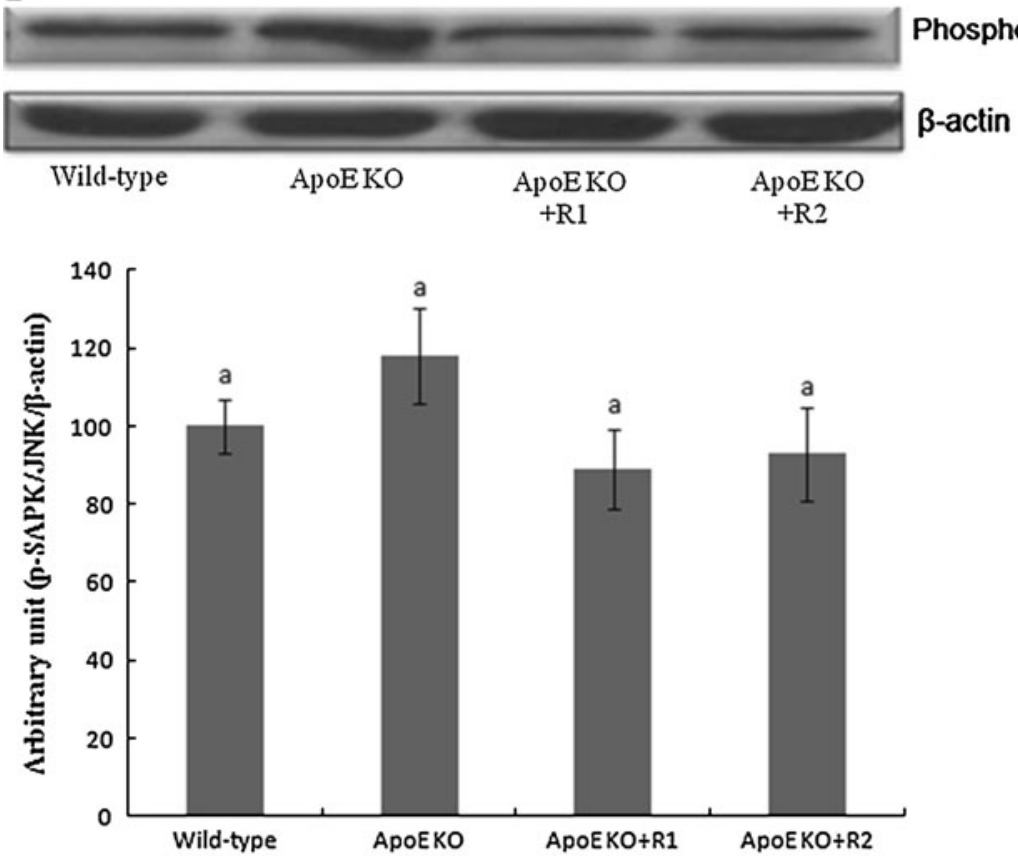

E
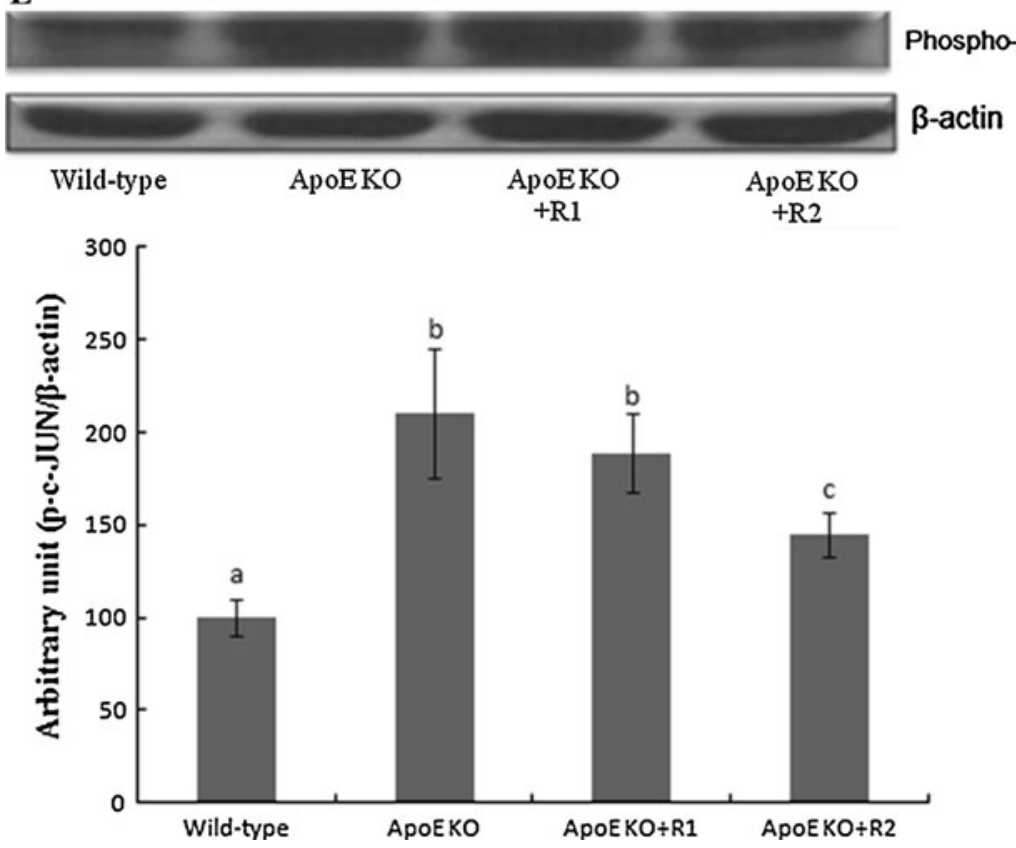

Effect of PDs and PTs ginsenosides combination on liver inflammation

The effects of ginsenosides combination on protein levels concerned with the inflammatory state of the liver in the hyperlipidemic mice were evaluated by Western blot analysis (Fig. 2). The hepatic protein level of $\mathrm{I} \kappa \mathrm{B}-\alpha$ showed a significant increase in R1 and R2 treatment groups compared with that of the hyperlipidemic mice.
The protein level of COX-2 in the liver was decreased in the groups that were administered the R1 and R2 ginsenosides combination by 0.6 - and 0.5 -fold, respectively, compared with the hyperlipidemic mice. Although the hepatic phospho-ERK 1/2 protein level was not different between the wild-type control mice and the hyperlipidemic mice, the protein level of the R1 and R2 ginsenoside combination groups was significantly decreased as compared to that of the hyperlipidemic mice. Moreover, the 
Fig. 3 Regulation of PD/PT ratio suppresses induction of apoptosis in hepatic cytosol by atherogenic diet in hyperlipidemic mice. Differences between means were analyzed by one-way analysis of variance followed by Duncan's test $(P<0.05)$. The bars indicate the means $\pm \mathrm{SD}$

\section{A}
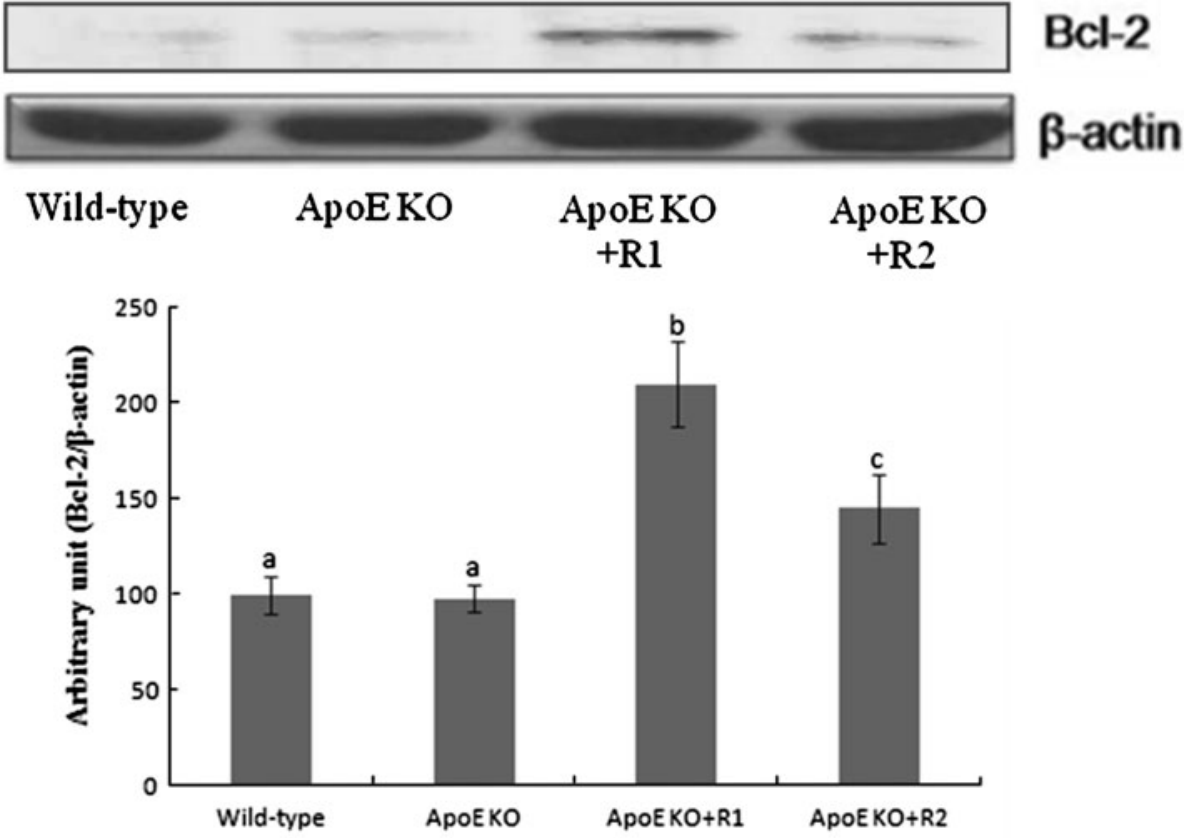

B
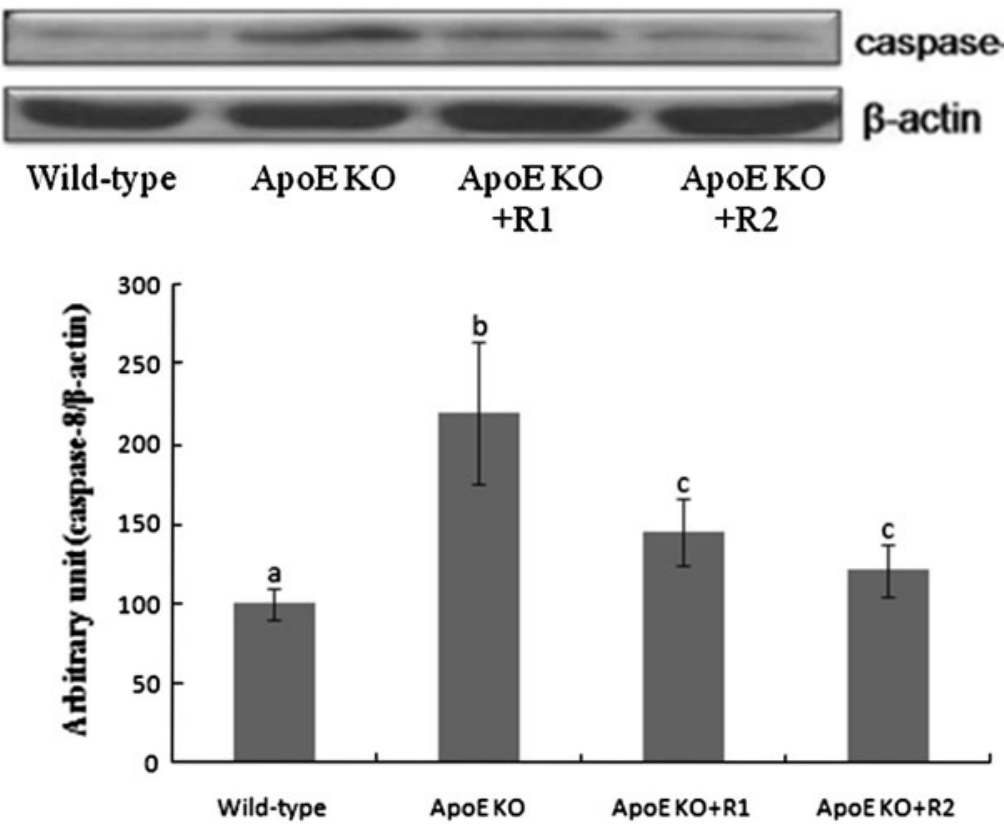

hepatic phospho-c-JUN protein level in the hyperlipidemic mice was increased compared with the wild-type mice by 2.1-fold. However, the hyperlipidemic mice that were administered $100 \mathrm{mg} / \mathrm{kg}$ of R2 showed a significant decrease in the hepatic phospho-c-JUN protein level by 0.7 -fold. There was no significant difference among all the groups in terms of the hepatic phospho-SAPK/JNK protein level.
Effect of PDs and PTs ginsenosides combination on liver apoptosis

Figure 3 shows the effect of the ginsenosides combination on apoptosis under a high-cholesterol diet. Bcl-2, the antiapoptotic protein, in both the wild-type control mice and the hyperlipidemic mice was not different, whereas the R1 and R2 ginsenosides combination led to a significant 
Fig. 3 continued

C
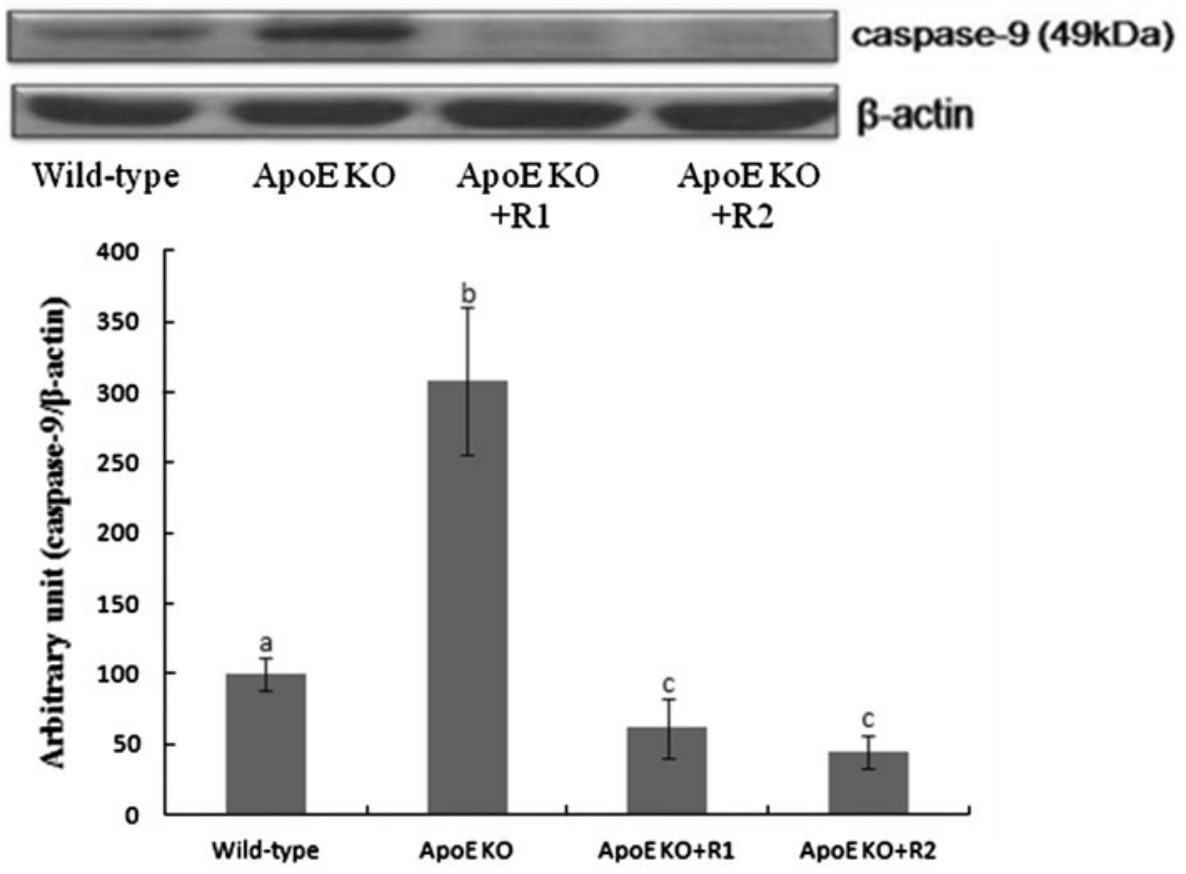

D
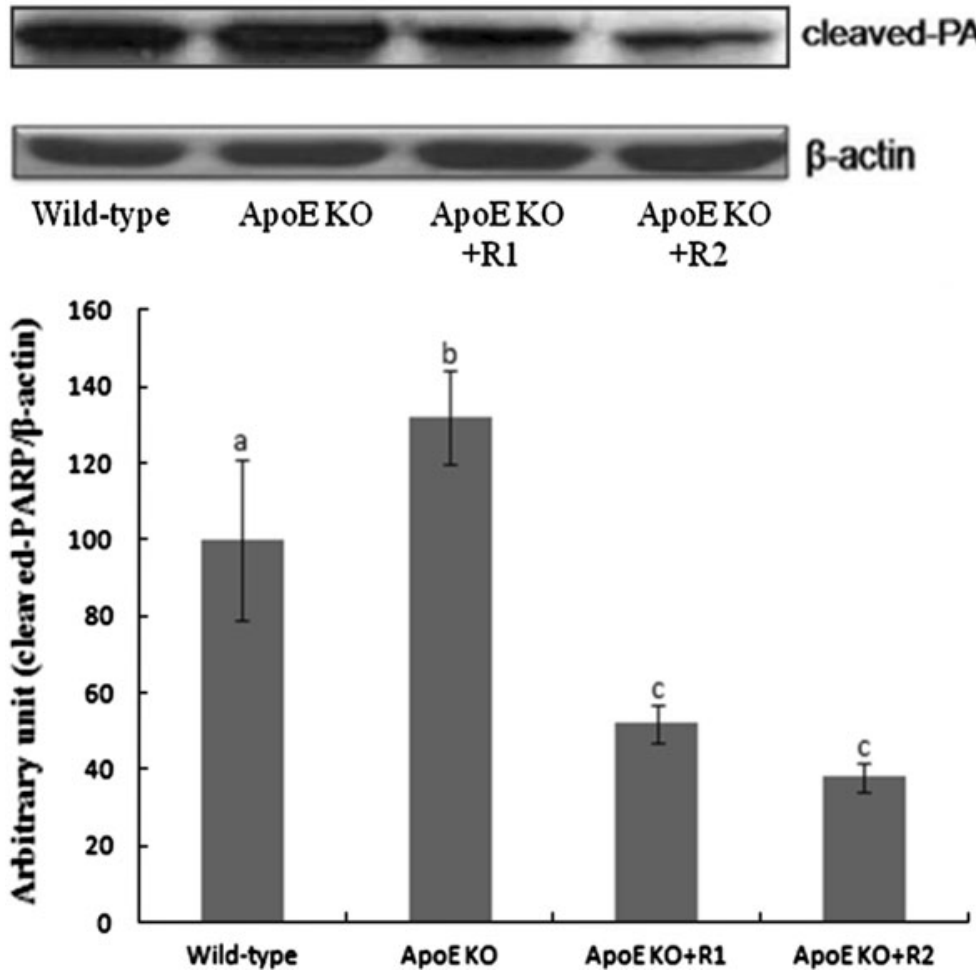

increase by 2.1 - and 1.5-fold, respectively. Furthermore, the R1 and R2 ginsenosides combination attenuated an increased caspase-8, -9, and cleaved-PARP protein expression shown in the hyperlipidemic mice.

\section{Discussion}

Ginseng is considered a valuable natural herb in the East as well as the West. Although most research has shown that 
there were no side effects of ginseng extracts, several studies reported that various saponins extracted from herbal plants facilitate hemolysis or exert hepatic toxicity (Lee et al. 2009). In our study, the administration of $100 \mathrm{mg} / \mathrm{kg}$ of ginseng extract did not demonstrate any hepatic damages as well as other studies. After an intraperitoneal injection with ginseng powder $(50-100 \mathrm{mg} / \mathrm{kg})$ to the animals in Ben$\mathrm{zo}(\alpha)$ pyrene induced liver damage, serum levels of aspartate aminotransferase (AST) and alanine transaminase (ALT) were significantly decreased (Kim et al. 2007). The red ginseng extract $(50-100 \mathrm{mg} / \mathrm{kg}$ ) also reduced the activity of AST and ALT in carbon tetrachloride induced liver injury (Lee et al. 2003). We have even found that an R1 ginsenosides combination decreased the plasma levels of AST and ALT in hyperlipidemia mice (Jang 2008). Therefore, we determined the standard levels of injection by the amount of injection when AST/ALT activity was improved. We have now extended our ginseng studies to the apoE KO mouse model that exhibits advanced atherosclerosis, increased tissue oxidation, and altered immune system.

$\mathrm{R} 1$ contained richer amounts of ginsenoside $\mathrm{Rb}_{1}, \mathrm{Rb}_{2}$, and $\mathrm{Rc}$ than $\mathrm{R} 2$. It was confirmed that the $\mathrm{R} 1$ exerted a protective effect against hepatic injury prompted by $\mathrm{H}_{2} \mathrm{O}_{2}$ treatment in previous studies (Lee et al. 2009). Also, previous studies reported that PD types of ginsenosides were effective not only in improving conditions of obesity, fatty liver, and hypertriglyceridemia in rodent models fed with a high-fat diet (Liu et al. 2010; Kim et al. 2009) but also in regulating inflammatory responses by inducing heme oxygenase (HO)-1, inhibiting inducible nitric oxide synthase (iNOS), and suppressing the tumor necrosis factor (TNF)- $\alpha$ expression in vitro (Lee et al. 2005; Cho et al. 2006). Moreover, ginsenoside PTs inhibit energy gain and normalize hypothalamic neuropeptides associated with the control of obesity in rats (Kim et al. 2009) and have a cytoprotective effect through their action against oxidative stress by blocking an increase in LPS-induced iNOS and $\mathrm{COX}-2$ expressions via control of $\mathrm{NF} \kappa \mathrm{B}$, which may be responsible for the chemoprevention of inflammatory diseases (Kwok et al. 2010; Oh et al. 2004). Thus, these data suggest that the ginsenosides combination with different ratios may affect hyperlipidemia and its related inflammatory response in liver.

Cell death plays an important role in immunogenesis, during inflammation and in the resolution of inflammatory reactions. The mechanisms and mediators involved have not yet been fully elucidated, but there is evidence that surrounding cells adjacent to inflammation kill themselves by apoptosis, increasing the damage caused by inflammatory reactions. One of the major pro-inflammatory factors, TNF$\alpha$, is involved in insulin resistance, inflammatory reactions, and cell apoptosis via various pathways. It also activates JNK and NF- $\kappa$ B (Zhang et al. 2008; Hotamisligil et al. 1993;
Feinstein et al. 1993). MAPKs such as ERK1/2, JNK, p38 MAP kinase, PI3 K/PKB, and SAPK regulate inflammatory reactions, proliferation, differentiation, apoptosis, and survival of cells (Lin et al. 2007). PDs that have higher levels of $\mathrm{Rb} 1$ and Rd are a TNF- $\alpha$ antagonist, and they lower the synthesis of TNF- $\alpha$ through the inhibition of COX-2, phospho-ERK, and c-Jun expression (Widmann et al. 1999). In this study, the R2 ginsenosides combination was significantly effective in blocking the MAPK signaling pathway, such as c-Jun phosphorylation, and in inhibiting the expression of COX-2, even though both R1 and R2 treatments inhibited $\mathrm{I} \kappa \mathrm{B}-\alpha$ degradation. Caspase- 8 is the most proximal caspase to become activated upon ligation of the Fas molecule. Caspase- 8 also cleaves Bid to produce tBid fragments, which then relocates to the mitochondria to further alter the mitochondrial membrane. The mitochondriamediated pathway results in the activation of caspase- 3 and caspase- 9 , which then activates downstream caspase- 8 (Oh and Lee 2004). Our data showed that an R1 and R2 ginsenosides combination increased the expression of $\mathrm{Bcl}-2$, whereas those treatments suppressed the expression of apoptotic signals, caspase-8/-9, and cleaved PARP. Therefore, R1 and R2 had potential anti-proinflammatory and antiapoptotic effects in the liver of hyperlipidemic mice.

The present study showed that the plasma lipid profiles and AI were higher in hyperlipidemic mice that were fed a high-cholesterol diet, whereas the administration of an R1 and R2 ginsenosides combination selectively attenuated the changes. We found that ginseng extract $(\mathrm{PD} / \mathrm{PT}=1: 1)$ had anti-apoptotic effect on TUNEL-induced apoptotic cardiomyocyte of high-cholesterol fed apo E KO mice. And TC- and TG-fed cholesterol plus $\mathrm{PD} / \mathrm{PT}=1: 1$ were also decreased in heart tissues by more than $200 \%$ compared to apoE KO-fed high cholesterol (Jang 2008). However, this study was performed for the comparison of 1:1 versus 2:1 of $\mathrm{PD} / \mathrm{PT}$ to prevent cholesterol-derived fatty liver in apoE $\mathrm{KO}$ mice with mechanism of systemic inflammation. Inflammation causes alteration of lipid metabolism that, in turn, makes worse the inflammatory response by leading to a malicious cycle (Hotamisligil 2006; Khovidhunkit et al. 2004). Improvement of lipid metabolism disorders was beneficial to recovering from inflammation, and, in turn, the anti-inflammatory effect of Panax notoginseng saponins maintained a balanced lipid metabolism (Liu et al. 2010). The PDs and PTs ginsenosides combination obstructed the vicious cycle via regulation of lipid profiles in the plasma and liver as well as the anti-inflammatory response. Moreover, while the R2 ginsenosides combination decreased the hepatic TG level in hyperlipidemic mice, the R1 treatment was effective on an increased plasma TC level in the hyperlipidemic mice. In previous studies, the oral administration of $\mathrm{Re}$, which is an abundant ginsenoside in R2, has shown to induce an 
anti-hypercholesterolemic effect in an STZ-induced diabetic rat (Cho et al. 2006). The i.p. injection of $\mathrm{Rb}_{1}(10 \mathrm{mg} /$ $\mathrm{kg}$ ), in which R1 is plentiful, displayed a tendency to lower the AI-2 (TG/HDL), but it did not affect the serum lipid profiles in rats (Park et al. 2002). Therefore, the effect of the R1 and R2 ginsenosides combination on the lipid profile may be dependent on its composition of ginsenosides and tissue applied. This is also connected with other study that a close interrelation between regulators of lipid metabolism and systemic inflammation. It showed the amount of atherosclerosis is associated with macrophages and T-cells within plaques and adipose tissue and correlates with plasma cholesterol values (Lohmann et al. 2009).

MDA, the final product of LPO, is highly cytotoxic and exerts oxidative injury to the cell. Previous research has recently shown that dietary cholesterol contributes to the development of hepatic inflammation (Wouters et al. 2008; Mari et al. 2006; Vergnes et al. 2003). Increased levels of oxidized cholesterol products have been shown to induce oxidative stress (Wouters et al. 2008; Ferre et al. 2009). In our study, while an R1 and R2 ginsenosides combination decreased the plasma MDA level in hyperlipidemic mice, an R1 treatment reduced the LPO level in both the plasma and liver, suggesting that the ginsenosides combination, either R1 or R2, showed a tissue-specific effect toward reducing oxidative stress. In previous studies, the MDA levels in the kidney and eye were significantly reduced in diabetic rats treated with $20 \mathrm{mg} / \mathrm{kg}$ ginsenoside Re, the main constituent in R2, whereas the MDA level in the aorta was not significantly altered (Cho et al. 2006). The study also demonstrated that administration of Re is needed to reduce the activity of ROS in diabetic rats and to induce the protective effect against oxidative stress (Cho et al. 2006).

In conclusion, the administration of a combination of PDs and PTs ginsenosides demonstrated a preventive effect on liver inflammation and apoptosis in hyperlipidemic apo E KO mice through the modulation of oxidative stress.

Acknowledgments This study was carried out with the support of "Specific Joint Agricultural Research-promoting Projects (No.1050053, 2004-2007)," Seoul R \& BD Program (10526) and Ministry of Health and Welfare (A00385), Republic of Korea. In the third year, the Advanced Research Program (AP) of the Seoul Science High School for Gifted Students joined our university-wide ginseng project.

Conflicts of interest None.

\section{References}

Ajizian SJ, English BK, Meals EA (1999) Specific inhibitors of p38 and extracellular signal-regulated kinase mitogen-activated protein kinase pathways block inducible nitric oxide synthase and tumor necrosis factor accumulation in murine macrophages stimulated with lipopolysaccharide and interferon-gamma. J Infect Dis 179:939-944
Boulton TG, Nye SH, Robbins DJ, Ip NY, Radziejewska E, Morgenbesser SD, DePinho RA, Panayotatos N, Cobb MH, Yancopoulos GD (1991) ERKs: a family of protein-serine/ threonine kinases that are activated and tyrosine phosphorylated in response to insulin and NGF. Cell 65:663-675

Bray GA, Popkin BM (1998) Dietary fat intake does affect obesity. Am J Clin Nutr 68:1157-1173

Chen LF, Greene WC (2004) Shaping the nuclear action of NF-kappaB. Nat Rev Mol Cell Biol 5:392-401

Cho JY, Yoo ES, Cha BC, Park HJ, Rhee MH, Han YN (2006a) The inhibitory effect of triterpenoid glycosides originating from Sanguisorba officinalis on tissue factor activity and the production of TNF-alpha. Planta Med 72:1279-1284

Cho WC, Chung WS, Lee SK, Leung AW, Cheng CH, Yue KK (2006b) Ginsenoside Re of Panax ginseng possesses significant antioxidant and antihyperlipidemic efficacies in streptozotocininduced diabetic rats. Eur J Pharmacol 550:173-179

Farrell GC, Larter CZ (2006) Nonalcoholic fatty liver disease: from steatosis to cirrhosis. Hepatology 43:S99-S112

Feinstein R, Kanety H, Papa MZ, Lunenfeld B, Karasik A (1993) Tumor necrosis factor- $\alpha$ suppresses insulin-induced tyrosine posphorylation of insulin receptor and its substrate. J Biol Chem 268:26055-26058

Ferre N, Martinez-Clemente M, Lopez-Parra M, Gonzalez-Periz A, Horrillo R, Planaguma A, Camps J, Joven J, Tres A, Guardiola F, Bataller R, Arroyo V, Claria J (2009) Increased susceptibility to exacerbated liver injury in hypercholesterolemic ApoE-deficient mice: potential involvement of oxysterols. Am J Physiol Gastrointest Liver Physiol 296:G553-G562

Formiguera X, Canton A (2004) Obesity: epidemiology and clinical aspects. Best Pract Clin Gastroenterol 18:1125-1146

Gordon T, Castelli WP, Hjortland MC, Kannel WB, Dawber TR (1977) High density lipoprotein as a protective factor against coronary heart disease. The Framingham Study. Am J Med 62:707-714

Guo Y, Zhang C, Du X, Nair U, Yoo TJ (2005) Morphological and functional alterations of the cochlea in apolipoprotein $\mathrm{E}$ gene deficient mice. Hear Res 208:54-67

Hotamisligil GS (2006) Inflammation and metabolic disorders. Nature 444:860-867

Hotamisligil GS, Shargill NS, Spiegelman BM (1993) Adipose expression of tumor necrosis factor-alpha: direct role in obesitylinked insulin resistance. Science (NY) 259:87-91

Jang SJ, Kim SS, Lee M (2008) Hypolipidemic and antioxidant effects to ginseng extract (PD:PT = 1) in Apo E Null Mice. Korean J Nutr 41(7):594-601

Jou J, Choi SS, Diehl AM (2008) Mechanisms of disease progression in nonalcoholic fatty liver disease. Semin Liver Dis 28:370-379

Khovidhunkit W, Kim MS, Memon RA, Shigenaga JK, Moser AH, Feingold KR, Grunfeld C (2004) Effects of infection and inflammation on lipid and lipoprotein metabolism: mechanisms and consequences to the host. J Lipid Res 45:1169-1196

Kim H-J, Bo M-H, Lee J-W, Im H-G, Lee I-S (2007) Antioxidant effects of ginseng powder on liver on benzo $(\alpha)$ pyrene-treated mice. Korean J Food Sci Technol 39(2):217-221

Kim JH, Kang SA, Han SM, Shim I (2009) Comparison of the antiobesity effects of the protopanaxadiol- and protopanaxatrioltype saponins of red ginseng. Phytother Res 23:78-85

Kwok HH, Ng WY, Yang MS, Mak NK, Wong RN, Yue PY (2010) The ginsenoside protopanaxatriol protects endothelial cells from hydrogen peroxide-induced cell injury and cell death by modulating intracellular redox status. Free Radic Biol Med 48:437-445

Kyriakis JM, Banerjee P, Nikolakaki E, Dai T, Rubie EA, Ahmad MF, Avruch J, Woodgett JR (1994) The stress-activated protein kinase subfamily of c-Jun kinases. Nature 369:156-160 
Lee M, Bae MA (2007) Docosahexaenoic acid induces apoptosis in CYP2E1-containing HepG2 cells by activating the c-Jun N-terminal protein kinase related mitochondrial damage. J Nutr Biochem 18:348-354

Lee JC, Laydon JT, McDonnell PC, Gallagher TF, Kumar S, Green D, McNulty D, Blumenthal MJ, Heys JR, Landvatter SW, Strickler JE, McLaughlin MM, Siemens IR, Fisher SM, Livi GP, White JR, Adams JL, Young PR (1994) A protein kinase involved in the regulation of inflammatory cytokine biosynthesis. Nature 372:739-746

Lee CK, Han YN, Kim NY, Choi JW (2003) The therapeutic effects of Korean ginsneg on carbone tetrachrolide- and galactosamineinduced hepatotoxicity. J Ginseng Res 27:1-10

Lee SH, Seo GS, Ko G, Kim JB, Sohn DH (2005) Anti-inflammatory activity of 20(S)-protopanaxadiol: enhanced heme oxygenase 1 expression in RAW 264.7 cells. Planta Med 71:1167-1170

Lee M, Sorn S, Baek S, Jang S, Kim S (2009) Antioxidant and apoptotic effects of Korean white ginseng extracted with the same ratio of Protopanaxadiol and Protopanaxatriol saponins in human hapatoma hepG2 cells. Ann N Y Acad Sci 1171:217-227

Lin WM, Zhang YM, Moldzio R, Rausch WD (2007) Ginsenoside Rd attenuates neuroinflammation of dopaminergic cells in culture. J Neural Transm Suppl 72:105-112

Liu CX, Xiao PG (1992) Recent advances on ginseng research in China. J Ethnopharmacol 36:27-38

Liu G, Wang B, Zhang J, Jiang H, Liu F (2009) Total panax notoginsenosides prevent atherosclerosis in apolipoprotein E-knockout mice: Role of downregulation of CD40 and MMP-9 expression. J Ethnopharmacol 126:350-354

Liu R, Zhang J, Liu W, Kimura Y, Zheng Y (2010a) Anti-obesity effects of protopanaxdiol types of Ginsenosides isolated from the leaves of American ginseng (Panax quinquefolius L.) in mice fed with a high-fat diet. Fitoterapia 81:1079-1087

Liu Y, Zhang HG, Jia YY, Li XH (2010b) Panax notoginseng saponins attenuate atherogenesis accelerated by zymosan in rabbits. Biol Pharm Bull 33:1324-1330

Lohmann C, Schäfer N, Lukowicz TV, Stein S, Borén J, Rütti S, Wahli W, Donath MY, Lüscher TF, Christian Matter M (2009) Atherosclerotic and visceral adipose tissue, liver, and pancreatic islet. Atherosclerosis 7(2):360-367

Mari M, Caballero F, Colell A, Morales A, Caballeria J, Fernandez A, Enrich C, Fernandez-Checa JC, Garcia-Ruiz C (2006) Mitochondrial free cholesterol loading sensitizes to TNF- and Fasmediated steatohepatitis. Cell Metab 4:185-198

Mayr M, Mayr U, Chung YL, Yin X, Griffiths JR, Xu Q (2004) Vascular proteomics: linking proteomic and metabolomic changes. Proteomics 4:3751-3761

Oh SH, Lee BH (2004) A ginseng saponin metabolite-induced apoptosis in HepG2 cells involves a mitochondria-mediated pathway and its downstream caspase- 8 activation and Bid cleavage. Toxicol Appl Pharmacol 194:221-229

Oh GS, Pae HO, Choi BM, Seo EA, Kim DH, Shin MK, Kim JD, Kim JB, Chung HT (2004) 20(S)-Protopanaxatriol, one of ginsenoside metabolites, inhibits inducible nitric oxide synthase and cyclooxygenase-2 expressions through inactivation of nuclear factor-kappaB in RAW 264.7 macrophages stimulated with lipopolysaccharide. Cancer Lett 205:23-29

Park KH, Shin HJ, Song YB, Hyun HC, Cho HJ, Ham HS, Yoo YB, Ko YC, Jun WT, Park HJ (2002) Possible role of ginsenoside $\mathrm{Rb} 1$ on regulation of rat liver triglycerides. Biol Pharm Bull 25:457-460

Pearson G, Robinson F, Beers Gibson T, Xu BE, Karandikar M, Berman K, Cobb MH (2001) Mitogen-activated protein (MAP) kinase pathways: regulation and physiological functions. Endocr Rev 22:153-183

Pendino GM, Mariano A, Surace P, Caserta CA, Fiorillo MT, Amante A, Bruno S, Mangano C, Polito I, Amato F, Cotichini R, Stroffolini T, Mele A, ACE Collaborating Group (2005) Prevalence and etiology of altered liver tests: a population-based survey in a Mediterranean town. Hepatology 41:1151-1159

Shibata S, Tanaka O, Ando T, Sado M, Tsushima S, Ohsawa T (1966) Chemical studies on oriental plant drugs. XIV. Protopanaxadiol, a genuine sapogenin of ginseng saponins. Chem Pharm Bull (TOKYO) 14:595-600

Valen G, Yan ZQ, Hansson GK (2001) Nuclear factor kappa-B and the heart. J Am Coll Cardiol 38:307-314

Vassault A, Sebille L, Bailly M (1981) Evaluation according to the NCCLS protocol of the Kodak-Ektachem procedure applied to the estimation of glucose and urea in plasma (author's transl). Ann Biol Clin 39:17-28

Vergnes L, Phan J, Strauss M, Tafuri S, Reue K (2003) Cholesterol and cholate components of an atherogenic diet induce distinct stages of hepatic inflammatory gene expression. J Biol Chem 278:42774-42784

Wan JB, Lee SM, Wang JD, Wang N, He CW, Wang YT, Kang JX (2009) Panax notoginseng reduces atherosclerotic lesions in ApoE-deficient mice and inhibits TNF-alpha-induced endothelial adhesion molecule expression and monocyte adhesion. J Agric Food Chem 57:6692-6697

Widmann C, Gibson S, Jarpe MB, Johnson GL (1999) Mitogenactivated protein kinase: conservation of a three-kinase module from yeast to human. Physiol Rev 79:43-80

Wouters K, van Gorp PJ, Beighs V, Gijbels MF, Lutjohann D, Kerksiek A, van Kruchten R, Maeda N, Staels B, van Bilsen M, Shiri-Sverdlov R, Hofker MH (2008) Dietary cholesterol, rather than liver steatosis, leads to hepatic inflammation in hyperlipidemic mouse models of nonalcoholic steatohepatitis. Hepatology 48:474-486

Xie JT, Mehendale SR, Li X, Quigg R, Wang X, Wang CZ, Wu JA, Aung HH, Rue AP, Bell GI, Yuan CS (2005) Anti-diabetic effect of ginsenoside $\mathrm{Re}$ in ob/ob mice. Biochim Biophys Acta 1740:319-325

Zhang Z, Li X, Lv W, Yang Y, Gao H, Yang J, Shen Y, Ning G (2008) Ginsenoside Re reduces insulin resistance through inhibition of c-Jun NH2-terminal kinase and nuclear factorkappaB. Mol Endocrinol (Baltimore, Md) 22:186-195 